\title{
Educational Games for Learning
}

\author{
Peña-Miguel Noemí, Sedano Hoyuelos Máximo \\ University of the Basque Country UPV/EHU, Bilbao, Bizkaia, Spain \\ *Corresponding Author: noemi.pena@ehu.es
}

Copyright @ 2014 Horizon Research Publishing All rights reserved.

\begin{abstract}
The introduction of new technologies in society has created a need for interactive contents that can make the most of the potential that technological advances offer. Serious games as educational games are such content: they can be defined as video games or interactive applications whose main purpose is to provide not only entertainment but also training in areas such as health, marketing, education, etc. This paper reviews various cases of successful serious games and their influence on the learning process, looks at tutoring as the key to guiding the learning process throughout serious games and considers what kind of abilities and skills can be achieved via such games. At this time of financial, economic and social crisis citizens must be prepared to confront the challenges of the future, and the individual values of each citizen must be joined to those of society as a whole. Serious games are the perfect tool for achieving these aims, and for transmitting contents and values attractively and efficiently.
\end{abstract}

Keywords Serious Games, Tutoring, Game-Based Learning

\section{The Emergence of Serious Games}

\subsection{Their Potential}

There is no single definition of serious games, though they are generally held to be games used for training, advertising, simulation or education. Alternative definitions include the application of game concepts, technologies and ideas to non-entertainment applications. Clark Act was the first author who used this term in 1970. For him, serious games are effective teaching and training devices for students of all ages in many situations because they are highly motivating and because they communicate very efficiently the concepts and facts of many subjects. They offer us a rich field for a risk-free active exploration of serious intellectual and social problems (Act, 1970).

Serious games are simulations of real-world events or processes designed for the purpose of solving a problem (Sawyer, 2002). Although serious games can be entertaining, their main purpose is to train or educate users; they may also have other purposes such as marketing or advertising.

A game is a physical or mental contest played according to specific rules, with the goal of amusing or rewarding the participant. A video game is a mental contest played with a computer according to certain rules for amusement, recreation, or winning a stake, and a serious game is "a mental contest played with a computer in accordance with specific rules that uses entertainment to further government or corporate training, education, health, public policy, and strategic communication objectives" (Zyda, 2005).

The reintroduction of amusement has led to the appearance of the concept of edutainment (Prensky 2001 ;Gee 2007). The idea commonly defended is that the interest of learners in the subject will be increased by the pleasure and the wealth of experience gained during the game.

Generally they are designed in order to balance the subject matter with the game play and the ability of the player to retain and apply said subject matter to the real world. Video games are not the enemy, but the best opportunity we have to engage our kids in real learning process (Prensky 2003).

Michel et al. (2009) divide the history of serious games into four periods: first, with the arrival of learning machines and Pressey's Drum Tutor in 1924, learners became responsible for their own learning. Then simulation was introduced in 1946 with the MIT Whirlwind project, which enabled military airline pilots to train in a controlled situation. Learning was then achieved by trial and error in a systematic approach. The state of flow (Csíkszentmihályi, 1990) and immersion was thus found to increase. The democratization of video games then made simulators available to the general public. Michel et al. (2009) conclude their paper by stating that since the early 2000s simulation games have gradually become professionalized: Games are again being used in professional training, but in a broader way and not only for the acquisition of technical skills. Serious games can therefore be presented as technologies and video game platforms which have objectives other than mere entertainment (Michael \& Chen, 2006; Vorderer \& Ritterfeld, 2009). The associated virtual experience seems to be aimed at reengaging learners.

On the other hand, the potential of video games as vectors for learning was recognized from their outset (Malonne and Lepper, 1987). Indeed, numerous institutional studies 
(Federation of American Scientists, 2006; Project Tomorrow, 2008) confirmed the idea that video games could provide players with skills that were useful on a degree course and which could, moreover, be transferred to the business world. However, some researchers believe that regard for the intrinsic value of games as a means of education needs to be tempered (de Freitas, 2006; Pivec \& Pivec, 2009). There are two main reasons: on the one hand, the application of serious games in the field of education is very recent. On the other hand, little is known about the use of serious games in the education system, so data collection is a priority (Ulicsak \& Wright, 2010).

Besides, some initiatives were carried out, for example in 2002, the "Woodrow Wilson International Center" for Scholars in Washington D.C. launched a "Serious Games Initiative" to encourage the development of games that address policy and management issues. In 2008, Project Tomorrow in its report explained that educational games help today's students to be well prepared and to be tomorrow's innovators, leaders and engaged citizens of the world (Project Tomorrow, 2008).

In this way, nowadays, there is substantial interest in serious games for formal education, professional training, healthcare, advertising, public policy and social change.

Furthermore, games have become a new form of interactive content and game playing provides an interactive, collaborative platform for learning purposes: Digital games that allow collaborative learning produce new ideas as well as exchanging information, simplifying problems, and resolving tasks (Pivec \& Pivec, 2011).

The potential of serious games is also evident in the fact that they can easily be adapted to any technological format and can be used on desktop equipment or on mobile devices of all kinds such as iPads and tablets. However before they are implemented there are points that needs to be borne in mind: it is necessary to determine what the target audience is, how much time is available for the games and what skills and competences are to be promoted. Depending on these points, it must be decided which platforms are best suited to their implementation. The term "multiplatform" is used for all kinds of digital content. The appearance of programming environments such as HTML5 (at Internet browser level) and UNITY for downloadable applications on mobile devices enables serious games to be developed for various platforms simultaneously.

\subsection{The Relevancy of Tutoring}

One of the most crucial factors for successful educational games is their ability to maintain an individual learner's motivation and interest by adapting the individual learning and gaming experience to each learner's needs, preferences, goals, and abilities (Kickmeier-Rust et al 2011). In achieving this, the role of the tutor is highly important, and several researchers are working in this area. The idea comes from the field of adaptive/intelligent tutoring in conventional technology-supported teaching and learning, basically inspired by Benjamin Bloom, who stated in 1984 that students who received one-to-one tutoring performed on average as well as the top two percent of those receiving classroom instructions.

Since then psychologists, instructors, and technicians have attempted to develop technology capable of taking the role of a private teacher and intelligently providing individual learners with suitable tutoring. The spectrum of approaches, methods, frameworks, and applications used is quite broad (De Bra, 2008; Kinshuk, Lin, \& Patel, 2006).

Serious games need tutoring and dynamization: without them the learning process is not completed (Garris et al, 2002). This tutoring enables any abnormal behavior on the part of the user to be monitored, and helps prevent inappropriate behavior which is possible in theory but socially unacceptable (Wainess, 2007). It also helps promote the added value that serious games bring to the education process (on-site or on-line learning processes). The work involved in tutoring is the key to guiding the learning process throughout serious games. On the other hand, some researchers (Reese, 2007; Kearney and Pivec, 2007 b) believe that serious games help not only in the learning process but also in the user's training in the virtual world in which the game is conducted.

The tutor is an adviser in the education process: not only does he/she provide knowledge to a passive user as in the traditional education system, but the user also contributes his/her own previous skills and knowledge to the community. Therefore tutors and learners need to interact and collaborate within the education process (Pivec \& Pivec, 2011). The tutor seeks feedback after each decision is implemented.

Serious games need basically two elements: good tutoring and a dynamic setting. Otherwise the learning process is not completed (Garris et al, 2002). This tutoring enables any abnormal behavior on the part of the user to be monitored and helps avoid inappropriate behavior which is possible but socially unacceptable (Wainess, 2007). It also helps promote the added value that serious games bring to the education process (on-site or on-line learning processes). The work involved in tutoring is the key to guiding the learning process in serious games and that work should involve the following specific key points:

- Drawing up a list of the objectives to be pursued in the serious games used.

- Developing a teaching guide to determine what concepts are to be reinforced by the serious games and what competences they can be used to promote.

- Defining a framework for the tutor to follow and at the same time see if the aims have been met. In this sense, there must be continual feedback to address any points that might discourage the user (he/she cannot continue the game; he/she has difficulties or has started badly).

- Establishing a final feedback tool for the whole group to compare the results of each user in with those of the rest of the group.

- Assessing the opportunities for interaction provided, 
how and when the game triggers moments of reflection in the user experience and what assessment mechanisms it can handle for gauging the knowledge and understanding acquired by the learner (Michel et al, 2009).

- The use of serious games as a learning method in initial training needs to take into account the profiles of the learners and in particular their previous experience in the field studied. This could be monitored by suitable tutoring.

\section{Serious games that are Easy to Develop and Use}

We concentrate here on "academic serious games" which are used for simulation purposes in initial training.

\subsection{Panel}

Some researchers (Reese, 2007; Kearney and Pivec, 2007 b) believe that serious games not only help in the learning process but also increase users' knowledge of the virtual world or virtual space in which the game takes place.

In this game, the players have to answer questions on five topics distributed in five levels of difficulty. This game uses a question and answer format. When a player on one team does not know the answer the next team can answer the question. The rows show the five topics and the columns the five levels of difficulty. The objective is to obtain the highest score.

It is a game with a television format that involves different environment-related topics and is aimed at different age groups from primary school to secondary school levels. Serious games have also been used to encourage entrepreneurship and management at vocational training centres, in driving schools and in training processes in private and public-sector businesses.

Examples include the "Panel" simulator used to reinforce contents and help learners acquire a truck-driver's license (called CAP in Spain) and the online Clio Cup driving simulator, which accurately reproduces many details of this car racing competition in Spain.

The driving school that used this game is very content with the results obtained: $85 \%$ of users passed their truck-driver's license exam (Figure 1). They are now considering using another game to improve the results of people preparing to take their car driver's license exam.

This game has also been used at the University of Salamanca in Spain as a tool for reinforcing the knowledge of students in a marketing-related subject taught on the degree course in Economics and Management. The level of learner satisfaction was 7.8 points out of 10 . Students said that the format of the game was very dynamic and motivating. It caught their attention and enabled them to learn, compete and game at the same time.

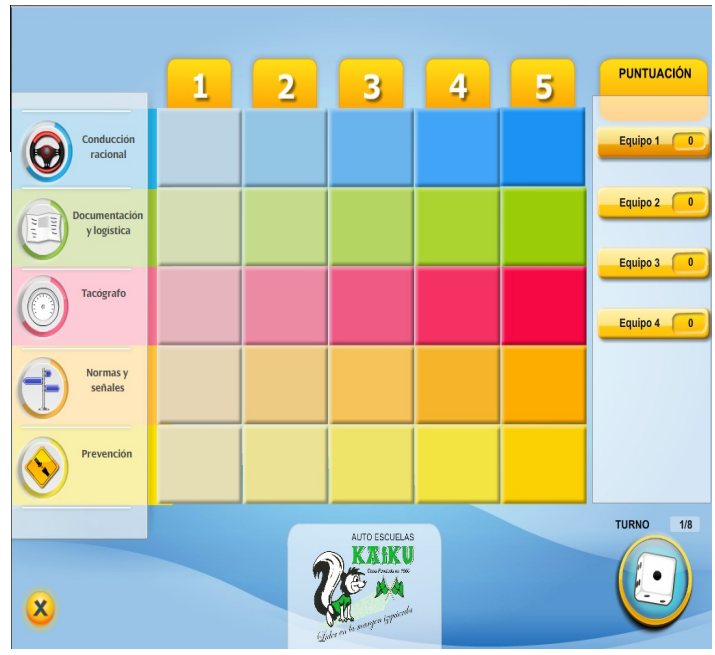

Source: www.gestionet.net

Figure 1. Screen from the Panel game

\subsection{Games for Learning Vocabulary and Numbers.}

Tik Tak Hitzak_and Tik Tak zenbakiak are two games for children aged 6 and over. The first is used to teach basic vocabulary in Basque, Spanish and English. The second is used to improve children's numeracy skills in basic operations such as additions, subtractions, multiplications and divisions. It features a character called Punttu, who takes the form of a punctuation mark and takes care of the language. The objective is for players to help him to guess the word or the number which should appear below each picture and thus get the maximum score. In the course of these games pictures appear on screen and the main character must fill the gaps with the help of the learner.

There are three levels of difficulty with a number of different screens featuring enemies and objects to help learners. In the easy and difficult levels the words have missing letters and Punttu must fill the gaps. Once one word is completed the next one appears, and so on.

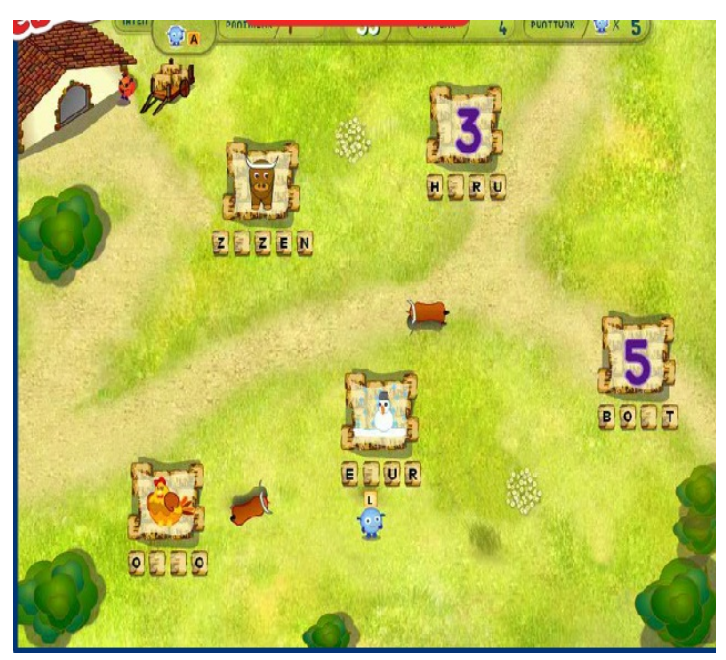

Source: Txapelgames.com

Figure 2. Example of Tik tak hitzak 
In this screenshot the main character "Punttu" (the blue dot in the middle of the screen) has to deal with bulls which appear suddenly and try to prevent him from completing the word (Figure 2).

These games have been used in some primary schools in the Basque Country and all the teachers involved say that the experience was very positive: students learnt new words easily and entertainingly.

Moreover, the level of attention shown by all pupils was higher when the teachers worked with these games in class.

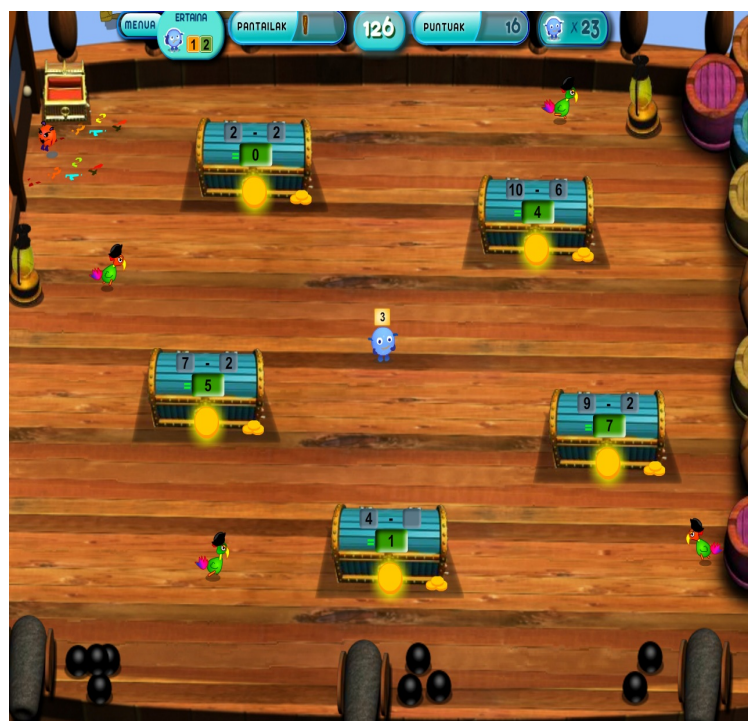

Source: Txapelgames.com

Figure 3. Sample of tik tak zenbakiak

In this game "Punttu" has to deal with birds that try to distract him.

$82.35 \%$ of parents who have gamed with their children say that both games are very useful in helping young children to learn basic vocabulary and basic mathematical operations (Figure 3). They therefore consider them to be valuable tools for improving children's learning.

\subsection{Games based on Trivial Pursuit and on the Game of Goose}

These are board games. Users have to answer to questions which are classified in five categories related to different topics.

This type of game is used in education to elicit questions and answers. The questions are grouped according to courses and subjects related to the curriculum of a specific education stage. Such games (America's Army, Triage Trainer) have begun to be used also in adult training with contents such as sustainability, environmental matters and management. In some countries the game of Goose is better known as Snakes and Ladders (Great Britain or USA).

An example is the game "A Day On the Trail", which is undoubtedly dynamic and entertaining. In this game children learn about green trails in a pleasant, entertaining, original way. It consists of a virtual board that simulates a green trail with all its typical elements: tunnels, bridges, stations, plants, and animals. This game was designed for Fundación de los Ferrocarriles Españoles [Spanish Railway Foundation] to make people aware of the former railway lines that had been turned into walking trails (Figure 4).

The players advance along the green trail whilst answering questions from different categories: the geography of the trail, its environment, its cultural heritage, environmental matters such as sustainability, health, road safety, etc..

It is an educational game aimed at children aged 8-12, and players can choose between two levels: one for ages 6 to 8 and the other for ages 9 to 12 .

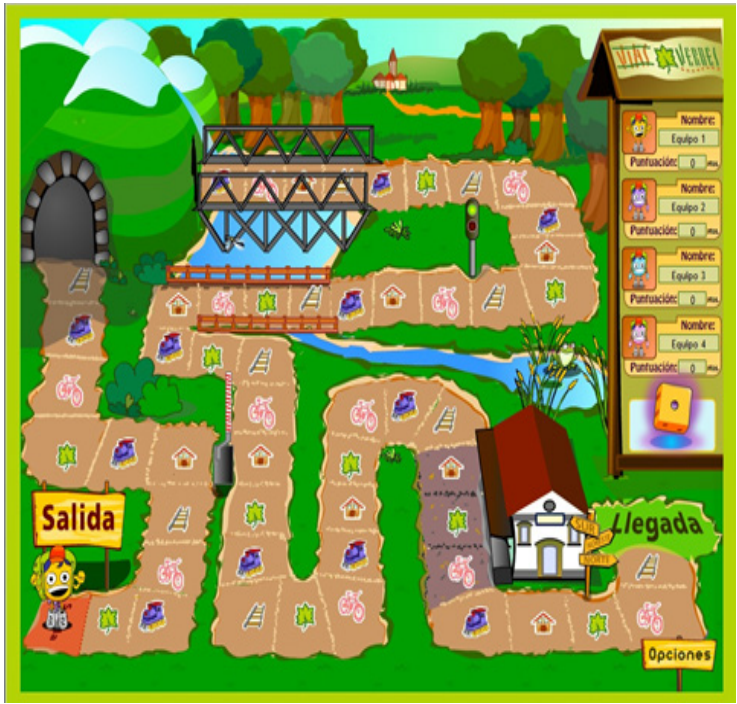

Source: www.viasverdes.com

Figure 4. Sample of the game "A Day On The Trail"

The results for this game were very interesting because not only the children but also their parents learnt a lot due to the huge range of themes and topics included.

It has been used at primary and secondary schools in Spain in working on matters of human and environmental assets.

Teachers value its simplicity and the way in which it motivates children. They value its combination of entertainment and education, which enables them to involve children in their own learning.

\section{Complex Serious Games for Working on Contents, Capacities and Competences: Games for Raising Competences and Skills: The "Island" Game}

\subsection{Development of the Game}

Games of this kind are used to promote innovation among university students of engineering and students at vocational training centres.

The skills and abilities that these games usually develop 
are sustainability, teamwork, solidarity, innovation, creativity, problem-solving, continuous improvement, energy efficiency, mathematical precision, initiative, goal achievement, result orientation, flexibility, and working with the environment.

The player is the mayor of the island and his/her aim is to maximize the welfare of the inhabitants (the best use of natural resources, $\mathrm{R} \& \mathrm{D}$, infrastructures). He/she must manage the economy of the island to achieve the most sustainable balance (Figure 5).

On this island users have access to different sources of non-renewable energy: oil, natural gas and uranium. They also have renewable energy sources: water, the sun and the wind. Moreover, since they live on an island they must properly manage the little space that is available (Figure 6).

In short, the player is elected mayor of the island and his/her mission is to maximize the use of the resources available there. The strategies implemented must bear in mind the relevant framework of limitations just as occurs in reality in public management of resources, i.e. a budget comprising income and expenditure and possible new problems caused as a result of the decisions made and the space involved.

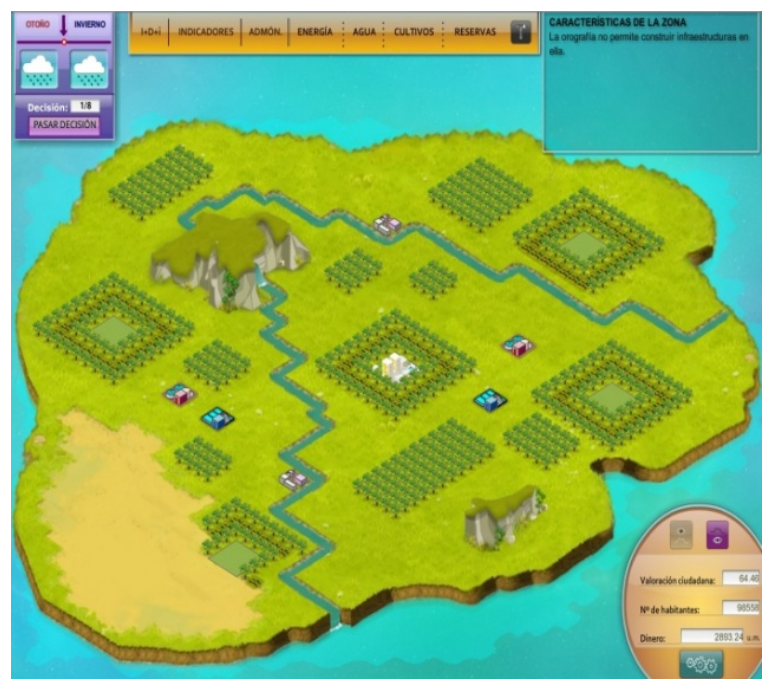

Source: www.simuladores-empresariales.com Figure 5. Screenshot of the "Island" Game

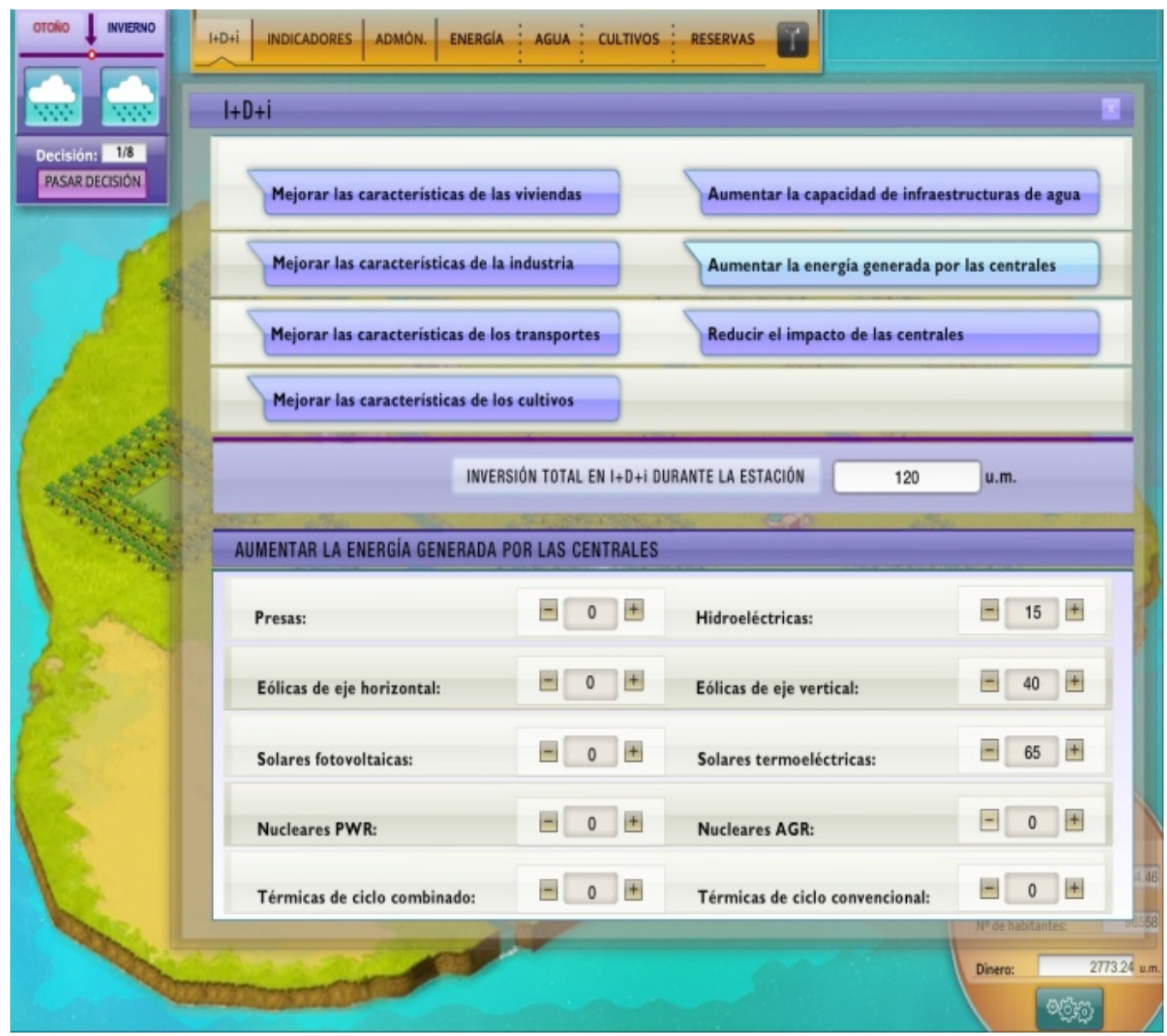

Source: www.simuladores-empresariales.com

Source: www.gestionet.net

Figure 6. A report showing results 


\subsection{Abilities and Skills that can be worked on in the "Island" Game}

Sustainability: The platform posits that the environment to be managed is highly fragile, and only very careful management which takes into account the environment as a valuable asset will enable the aims set to be reached.

Spirit of innovation: The key to progress in the game is for the player to bear innovation in mind as a necessary distinctive element that acts as a driver of competitiveness. This attitude must be applied especially when it becomes clear that strategic investments in R\&D\&i must almost always be made if suitable progress is to be achieved [it is impossible to obtain good results without engaging in research]. In any event, the application also gives the user room to show his/her spirit of innovation in applying imaginative solutions to problems that can be solved in a wide variety of ways.

Initiative and entrepreneurship: The game does not mark a path to be followed but rather offers different alternatives directly or indirectly, so it is the user as the manager of the island who must take the different decisions. Users are rewarded for showing initiative in anticipating future problems. In addition, the application is related to the processes of entrepreneurship in that the user takes the reins of an island that is going to experience major demographic expansion in relative terms.

Problem-solving: As users manage the island unforeseen circumstances will arise that must be solved in the best possible way. Budgetary restrictions will lead managers into dilemmas which must be solved by weighing up what is best for the citizenry.

Risk-taking: Users cannot predict everything that will happen in the coming seasons with absolute certainty. The climate, river levels, demographic flows, etc. can be predicted but not known for sure. Taking risks may be profitable in terms of results, but the citizenry will not forgive any mistakes committed. Whether or not risks are run will depend on the profile of each user, on how prone he/she is to take risks, and on his/her ability accurately to assess the scenarios that might arise if different types of risk are taken.

Continuous improvement: The game consists of continually bettering oneself. The population will keep growing and will shift between the old and new cities, so that the challenges that the manager faces will become more and more difficult.

Orientation towards quality: The options in the game that produce the best overall results are never the cheapest ones, but rather those that bring elements of quality to the island. In specific contexts the cheapest options might work as solutions, but in the long term the best way to obtain success is through research, investment in telecommunications, renewable energy sources, etc.

Value of effort: It takes effort to attain the aim of making progress season after season. Success is not a short-term aim but a long-distance race that takes work.

Mathematical skills: Many of the decisions to be made call for the ability to make mathematical calculations, to assess the likelihood of one event or another occurring, to determine what points of equilibrium enable the best outcomes to be obtained. Mathematical skills must also be used to obtain information from the application, from the present context and from past experiences.

Analytical skills: when the user has to take decisions, the ability to analyze all the information available is undoubtedly key if the right decisions are to be made. It is very important for users carefully to record all the information that they can possibly find in each season for reference in subsequent analyses.

Capability for planning and organization: This means the ability to determine effectively the ends, goals, aims and priorities of the tasks to be performed; to organize activities, their timing and the necessary resources and to monitor the processes established. The time-frame of the game is wide enough [several virtual years] for proper skills in planning to be highly important.

Strategy skills: On many occasions certain objectives will have to be abandoned and resources will need to be saved: Present aims must be sacrificed for the sake of reaping greater benefits in the future.

Technological competence: decisions must be taken bearing in mind that sophisticated technologies are being handled.

Information management capabilities: This means the ability to locate, select, order, relate, assess, and value information from different sources.

Independent learning: The ability to orient learning more and more independently, developing initiative and responsibility from one's own learning. The manual for the application is only the tip of the iceberg: When its explanations are insufficient it is the user him/herself who must draw conclusions and determine what courses of action may lead to the best results (even if those actions were not included in the explanations given to him/her).

Adaptability to different environments: This means the ability to adapt to different situations. The randomness of the game, risk, the variability of the flows between one season and another, etc., can lead the user to find him/herself in very different gaming contexts from one season to another.

Creativity: The ability to find new, different solutions when faced with conventional problems and situations. The platform proposes some rules of play with an environment and an operating system, but they can be managed in very different ways, and thinking differently may bring good results.

Accuracy: The ability to be accurate and to take care of every last detail of the decisions to be made.

Responsibility: Managing an entire island and all the resources involved is a big responsibility. No area should be neglected, and only proper, all-round management can maximize one's chances of remaining in one's post season after season.

Resource management: The manager has only limited resources available to try and reach the goals set: a budget 
that should preferably avoid too great a tax burden, oil reserves that are running out, and even limited physical space, because this is an island. Success in the game depends on managing these resources wisely, on being able to make savings and on investing in the right assets at the right time.

\subsection{Results of Using the "Island" Game}

For two years the Provincial Council of Vizcaya in the Basque Country has been staging a competition involving the use of the serious game of the Island. The participants are 300 university and vocational training students.

The purpose of the competition is to instill and foster skills and abilities in innovation, entrepreneurship, sustainability, public-sector economics, management of natural resources, initiative, client orientation and public awareness in young people.

An analysis of the results reveals the following: $70 \%$ of users obtained a high enough rating from the citizenry to pass the first case set and go on to the second. $80 \%$ of participants were studying for technical degrees or technical vocational training modules.

$85 \%$ of users gave the game a "very good" or "good" rating as a method for teaching how to manage a public-sector economy with its natural resources and public infrastructures so as to increase the welfare of citizens, while $15 \%$ rated it as "fair" or "unsuitable".

$90 \%$ of the teaching staff supporting the students in question considers that the game makes a valuable contribution to students' learning and gives them a practical insight into how public institutions manage natural resources and public infrastructures with a view to achieving a sustainable balance and increasing the welfare of society.

For the Provincial Council of Vizcaya in the Basque Country, this project provided a dynamic way of conveying and fostering a culture of innovation, competences and skills among the young people who will be the future managers of the province, oriented towards good public management of resources with a view to assuring better social and economic development.

The cooperation of technical experts from the Basque Government-dependent organization Ente Vasco de Energía ["Basque Energy Organization"] and civil engineering consultants from the Water Directorate at the Department of the Environment of the Regional Government of Cantabria was enlisted in setting up the energy and water infrastructures used in the game.

Mathematical algorithms were drawn up for the serious game to provide the basis for a mathematical model that relates the results obtained from the different endogenous variables calculated via the data entered in the exogenous variables that form part of the whole model.

The model that we have used in this study is the ordinary least squares (OLS) or linear least squares. It is a method for estimating the unknown parameters in a linear regression model. This method minimizes the sum of squared vertical distances between the observed responses in the dataset and the responses predicted by the linear approximation. The resulting estimator can be expressed by a simple formula, especially in the case of a single regressor on the right-hand side (Greene, 2002).

\subsection{Variables to Take into Account}

Aim $_{i}$ variable which shows if the student achieves the Serious Games' aims. (value 0 , value 1)

Score $_{i}$ Gained score using the Serious Game (from 0 to 10)

Ev.prev.skills ${ }_{i}$ Assessment of previous skills evaluation, that is, before the game was used.

Ev.gained.skills ${ }_{i}$ Assessment of gained skills after using the game

Studies $_{i}$ user's studies. ( $2=$ vocational training students, 3 = university students)

Hours ${ }_{i}$ Number of hours that student has dedicated using the game.

Age ${ }_{i}$ Age of the student

Our objective is to find the influence of these variables in the assessment of skills that have been gained after using the game. For this, we take as independent variables Aimi, Score i, Ev.prev.skills ${ }_{i}$, Studies ${ }_{i}$ Hours $_{i}$ Age $_{i}$ and the dependent variable is Ev.gained.skills ${ }_{i}$

In this way the first model is as follows:

$$
\begin{aligned}
& \text { Ev gainad skills }{ }_{i}-\beta_{1}+\beta_{2} \text { Aim }_{i}+\beta_{3} \text { Score }_{i}+\beta_{4} \text { Ev prev seills } \\
& i \\
& +\beta_{5} \text { Gentle }_{i}+\beta_{6} \text { Studies }_{i}+\beta_{7} \text { Howrs }_{i}+\beta_{8} A_{\text {Age }}+u_{i}
\end{aligned}
$$

After the model was estimated, we could conclude that three variables were not very significant in order to explain the assessment of gained skills after using the game. These variables were the gentle, the age and the studies, therefore they were excluded from the model. Concerning the gentle is not relevant for studying the gained skills and the age. According to the age of students, in the sample we are using a specific section of age between 18 and 26. Relating to the level of studies, due to both of type of students (university and vocational training students) has the same technical profile this variable has not a significant influence. Therefore, the final model is shown below.

\subsection{OLS Regression with Multiple Explanatory Variables}

$$
\begin{gathered}
\text { Ev.gained skills }{ }_{i}=\alpha_{1}+\alpha_{2} \text { Aim }_{i}+\alpha_{3} \text { Score }_{i} \\
+\alpha_{1} \text { Ev.prevskills } ;+\alpha_{\kappa} \text { Hours }_{i}+v_{i}
\end{gathered}
$$


Table 1. Estimations of OLS regression model

\begin{tabular}{|c|c|c|c|c|c|}
\hline & Coefficient & Deviance & t-Statistic & P-value & Significance \\
\hline const & 11.2976 & 1.60391 & 7.0438 & $<0.00001$ & $* * *$ \\
\hline Aim & 6.99099 & 1.24073 & 5.6346 & $<0.00001$ & $* * *$ \\
\hline Games_Score & 1.0398 & 0.341108 & 3.0483 & 0.00251 & $* * *$ \\
\hline Eva_Previous_Skills & 0.728603 & 0.0387086 & 18.8228 & $<0.00001$ & $* * *$ \\
\hline Hours_Of_Work & 0.850597 & 0.130969 & 6.4947 & $<0.00001$ & $* * *$ \\
\hline
\end{tabular}

Source: Own work

Once we have eliminated the no significant variables the obtained model shows us that the rest of variables are individually significant showing t-statistics $>2$ and F-statistics F $(4,295)=635.438$ (p-value $>0.000001)$.

As we can see analyzing the estimated regression coefficients, independent variables have a positive influence in the dependent variable as we supposed. This is due to the relationship that exists between one of each independent variables and the assessment of gained skills after using the game.

On the other hand, we get a good statistical alignment because of $89 \%$ of the dependent variable's variance has been adjusted. Thus, we can conclude this model is acceptable in order to considerate the influence of using this game to improve the student's skills after using the game (Table 1 and 2).

Table 2. Others estimations of OLS regression model

\begin{tabular}{|c|c|}
\hline Dependent variable mean & 808.975 \\
\hline Dependent variable's deviance & 154.648 \\
\hline Model sum-of-sq & 7436.38 \\
\hline Residual's deviance & 50.207 \\
\hline $\mathrm{R}^{2}$ & 0.896008 \\
\hline Ajusted $\mathrm{R}^{2}$ & 0.894598 \\
\hline F- Statistic $(4,295)$ & 635.438 \\
\hline
\end{tabular}

Source: Own work

\section{Conclusions}

The various cases of successful serious games examined in this paper enable us to conclude that the serious games have great potential for training because they have a highly positive effect on the learning process of users. This is due to the fact that they attract users in a simple, dynamic way and turn them into the protagonists of their own learning processes.

The aim of serious games goes beyond pure amusement: they seek to be a mechanism that reinforces learning in a dynamic, interactive, motivating and entertaining way.

Serious games are flexible enough to be accessible from any device including PCs, Macs, mobile phones, Ipads and tablets. The best technology for them is html 5 and Unity, which are well suited to the development of serious games.

Tutoring in serious games is the key: first because it facilitates the learning process, secondly because tutoring guides users in fulfilling their aims during the game, and thirdly because it provides a monitoring mechanism for preventing inappropriate behavior on the part of users. If serious games are used as a learning method in initial training the profiles of the learners must be taken into account, especially their previous experience in the field studied. This can be controlled by good tutoring.

Serious games can use gamification (the use of game thinking and game mechanics in a non-game context in order to engage users and solve problems) to provide a solution in any training process in any thematic area, because the serious games suited to the learning content to be taught can be developed.

In the context of our society, it must be highlighted that in these difficult times of financial, economic and social crisis in which we live, citizens must be prepared to face the challenges of the future, and the individual values of each citizen must be joined with those of society as a whole. Serious games are the perfect tool for reaching these aims, for transmitting contents and values attractively and efficiently, and for improving abilities and skills such as sustainability, strategic capabilities, information management capabilities, creativity, accuracy, responsibility and planning and organizational capabilities.

According to the Game of Island and using an ordinary least squares model we can conclude that after using the games the most of students have achieved to improve their skills in sustainability, teamwork, solidarity, innovation, creativity, problem-solving, continuous improvement, energy efficiency, mathematical precision, initiative, goal achievement, result orientation, flexibility, and working with the environment. This is due to the game has been a positive influence in the process of learning as the results of econometric model show us.

\section{REFERENCES}

[1] Abt, C (1970). Serious Games. New York: Viking Press 
[2] Csikszentmihalyi, M. (1990). Flow: The psychology of optimal experience. New York: Harper and Row.

[3] De Bra, P. M. E. (2008). Adaptive hypermedia. In Adelsberger, H. H., Kinshuk, J., Pawlowski, M.,\& Sampson, D. (Eds.), Handbook on Information Technologies for Education and Training (pp. 29-46). Berlin: Springer.

[4] de Freitas, S. (2006). « Learning in Immersive Worlds: A review of game-based learning ». Bristol. Joint Information System

[5] Federation of American Scientists. (2006). Harnessing the Power of Video Games for Learning. Proceedings of the Summit

Educational Games, October 25th, 2005, Washington DC. ht tp://www.fas.org/gamesummit/Resources/Summit\%20on\%2 0Educational\%20Games.pdf

[6] Garris, R et al (2002). Games, motivation and learning: A research and practice model. Simulation \& Gaming, vol $33 \mathrm{n}^{\circ}$ 4.

[7] Gee, J. (2007). Good video games and good learning: collected essays on video games, learning, and literacy. New York: Peter Lang.

[8] Greene, William H. (2002). Econometric analysis (5th ed.). New Jersey: Prentice Hall

[9] Kearney, P., Pivec, M (2007 b). Immersed and how? That is the question. Games in Action. Gothenburg, Sweden.

[10] Kickmeier-Rust, M; Mattheiss, E ;Steiner, C; Albert, D.(2011). A psycho-pedagogical Framework for Multi-Adaptive Educational Games. International Journal of Game-Based Learning. Vol 1, $\mathrm{n}^{\circ} 1$

[11] Kinshuk, L. T; Patel, A. (2006). User adaptation in supporting exploration tasks in virtual learning Environments. In Weiss, J., Nolan, J., Hunsinger, J., \& Trifonas, P. (Eds.). The International Handbook of Virtual Learning Environments (Vol. 1, pp. 395-425). Berlin: Springer.

[12] Malone, T. W; Lepper, M. R. (1987). Aptitude, learning and instruction iii: Cognitive and affective process analysis. Hillsdale, NJ: Lawrence Erlbaum Associates.

[13] Michel H; Kreziak D; Heraud J-M. (2009). Evaluation de la performance des Serious Games pour l'apprentissage : Analyse du transfert de comportement des éleveurs virtuels de Vacheland, Systèmes d'Information et Management Vol $14 n^{\circ} 4,2009$.
[14] Michael, D; Chen, S. (2006) Serious games: games that educate,train, and inform. Tampa, FL: Thomson.

[15] Pivec, P; Pivec, M. (2009). Games in Schools. European Commission (EC).

[16] Pivec, P; Pivec, M (2011): Digital Games: Changing Education, One Raid at a time. International Journal of Game-Based Learning. Vol 1, $\mathrm{n}^{\mathrm{o}} 1$.

[17] Prensky, M. (2001). Digital game-based learning. New York: McGraw-Hill.

[18] Prensky, M. (2003). Digital game-based learning. ACM Computers in Entertainment, Vol 1, $\mathrm{n}^{\mathrm{o}}$ 1. October, 2003, Book 02.

[19] Project Tomorrow. (2008) Speak Up 2007 for Students, Teachers, Parents \& School Leaders Selected National Findings-April 8, 2008

http://www.tomorrow.org/docs/national\%20findings\%20spe ak\%20up\%202007.pdf

[20] Reese, D. (2007). First steps and beyond: Serious games as preparation for future learning. Journal of Educational Multimedia and Hypermedia, 16(3), 283-300. Chesapeake, VA: AACE.

[21] Sawyer, B. (2002). Improving public policy through game-based learning and simulation, foresight and governance project: Woodrow Wilson International Center for Scholars, publication 20002-1.

[22] Vorderer, P; Ritterfeld, U. (2009). Digital games. In Nabi R,Oliver M, eds. The SAGE handbook of media processes and effects. Thousand Oaks, CA: Sage.

[23] Ulicsak, M; Wright, M. (2010). Games in education: Serious Games. Bristol, Futurelab 87pp.www.futurelab.org.uk/projec ts/games-in-education

[24] Wainess, R. (2007). «The potential of games \& simulations for learning and assessment », 2007 CRESST Conference: The Future of Test-based Educational Accountability. Los Angeles, CA.

[25] Zyda, M. (September 2005). From visual simulation to virtual reality to games. IEEE Computer.

[26] http://www.viasverdes.com/ViasVerdes/Varios/Juego\%20V $\%$ EDas\%20Verdes (visited on August 21st)

[27] www.gestionet.net

[28] www.simuladores-empresariales.com 